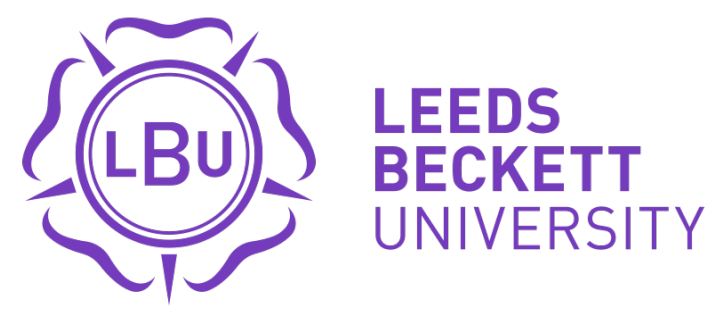

Citation:

Hobbs, M and Moltchanova, E and Wicks, C and Pringle, AR and Griffiths, C and Radley, D and Zwolinsky, S (2020) Investigating the environmental, behavioural, and sociodemographic determinants of attendance at a city-wide public health physical activity intervention: Longitudinal evidence over one year from 185,245 visits. Preventive Medicine. ISSN 0091-7435 DOI: https://doi.org/10.1016/j.ypmed.2020.106334

Link to Leeds Beckett Repository record:

https://eprints.leedsbeckett.ac.uk/id/eprint/7279/

Document Version:

Article (Accepted Version)

Creative Commons: Attribution-Noncommercial-No Derivative Works 4.0

The aim of the Leeds Beckett Repository is to provide open access to our research, as required by funder policies and permitted by publishers and copyright law.

The Leeds Beckett repository holds a wide range of publications, each of which has been checked for copyright and the relevant embargo period has been applied by the Research Services team.

We operate on a standard take-down policy. If you are the author or publisher of an output and you would like it removed from the repository, please contact us and we will investigate on a case-by-case basis.

Each thesis in the repository has been cleared where necessary by the author for third party copyright. If you would like a thesis to be removed from the repository or believe there is an issue with copyright, please contact us on openaccess@leedsbeckett.ac.uk and we will investigate on a case-by-case basis. 


\section{Investigating the environmental, behavioural, and sociodemographic determinants of attendance at a city-wide public health physical activity intervention: longitudinal evidence over one year from 185,245 visits}

\#,1,2Hobbs, M. ${ }^{3}$ Moltchanova, E. ${ }^{4}$ Wicks, C. ${ }^{5}$ Pringle, A. ${ }^{6}$ Griffiths, C. ${ }^{6}$ Radley, D. and ${ }^{7}$ Zwolinsky, S.

${ }^{1}$ GeoHealth Laboratory, Geospatial Research Institute, University of Canterbury, Christchurch, Canterbury, New Zealand

${ }^{2}$ Health Sciences, University of Canterbury, Christchurch, Canterbury, New Zealand.

${ }^{3}$ School of Mathematics \& Statistics, University of Canterbury, Christchurch, Canterbury, New Zealand.

${ }^{4}$ School of Health and Social Care, University of Essex, Colchester, United Kingdom.

${ }^{5}$ Sport, Outdoor \& Exercise Sciences, University of Derby, Derby, United Kingdom,

${ }^{6}$ Leeds Beckett University, Leeds, United Kingdom,

${ }^{7}$ West Yorkshire \& Harrogate Cancer Alliance, Wakefield, United Kingdom

\#Corresponding Author

Dr. Matthew Hobbs

Manawa Building, 276 Antigua Street, University of Canterbury - Te Whare Wānanga o Waitaha, Christchurch 8140, New Zealand.

matt.hobbs@canterbury.ac.nz 


\begin{abstract}
Understanding the determinants of attendance at public health interventions is critical for effective policy development. Most research focuses on individual-level determinants of attendance, while less is known about environmental-level determinants. Data were obtained from the Leeds Let's Get Active (LLGA) public health intervention in Leeds, England. Longitudinal data (April 2015 - March 2016) on attendance were obtained for 25,745 individuals (185,245 visits) with baseline data on sociodemographic determinants (e.g. age), lifestyle practices (e.g. smoking) obtained for 3,621 individuals. This resulted in a total of 744,468 days of attendance and non-attendance for analysis. Random forests were used to explore relative importance of the determinants of attendance while generalised linear models were applied to examine specific associations. The probability that a person will go more than once, the number of return visits, and the probability that a person will go on a particular day were investigated. Distance to leisure centre from home was the most influential determinant in predicting whether a person who went to the leisure centre once, returned. Age group was the most substantial determinant for the number of return visits. While distance to leisure centre was less important for predicting the number of return visits, the difference between the estimates for $300 \mathrm{~m}$ and $10,000 \mathrm{~m}$ was $7-10$ visits per year. Finally, month was the most important determinant of daily attendance. This longitudinal study highlights the importance of both individual and environmental determinants in predicting various aspects of attendance. It has implications for strategies aiming to increase attendance at public health interventions.
\end{abstract}




\section{Introduction}

Healthy lifestyles have long been acknowledged as being central to wellbeing and the prevention of disease (1). Presenting just one unhealthy behaviour can have a dramatic influence on mortality and non-communicable disease risk (2). When unhealthy lifestyle behaviours combine, the associated risk, rather than being additive, can elicit a multiplicative negative effect (3). The implications of this are profound given the regularity with which unhealthy lifestyle practices co-occur (4-7). Despite this, implementation of health-related policy and health improvement interventions have struggled to provide workable solutions and results particularly for deprived communities (8). As a result, socially disadvantaged individuals tend to engage in detrimental health behaviours more frequently due to a myriad of social, environmental, and behavioural determinants (9). What is more, unhealthy lifestyle practices - principally the lack of physical activity, smoking, diet and alcohol - have been described as the most proximal and most foundational risk factors for many non-communicable diseases (10), and are in the top ten leading causes of disability adjusted life years (11). Therefore, understanding the influential determinants associated with the successful implementation of public health interventions designed to address these issues will be fundamental for any public health system wishing to be successful and sustainable, particularly in deprived populations (12). Public health interventions can improve health behaviours and health outcomes in a diverse range of populations (13). However, evaluation of attendance at such interventions is seldom carried out using large-scale measurement data and is instead more often limited by small numbers of participants, based in small geographical areas with only cross-sectional or few observations (14).

Current evidence often focuses on the sociodemographic determinants of attendance at public health interventions. However, an enhanced understanding of how environmental determinants impact attendance at public health interventions are critical for the development of strategies that seek to improve them (15). For instance, wider structural, economic, and cultural determinants such as a fear of stigma (16), structural barriers such as accessing care due to lack of flexibility in opening hours (17), or irregular working hours $(18,19)$ may lead to poor adherence or retention at public health interventions. Considering wider determinants is especially important for interventions aimed at increasing physical activity (20), where day length and weather conditions have been identified as key determinants for participation (20-23). For example, the winter months, when the weather is cool and wet, and the evenings are darkest, generally produce the lowest activity levels $(24,25)$. Equally, excessive heat and humidity negatively impact participation (25). Although, unpleasant weather conditions (26) and an individual's age (27) influence physical activity participation outdoors, less is known about how these determinants influence participation in physical activity undertaken indoors (20). Indoor opportunities during cold wet months may help foster regular physical activity habits, especially among chronically inactive individuals who may struggle to enact health enhancing physical activity practices (22). However, a review found little support for the presumed environmental determinants of attendance and physical activity behaviour (28). Consequently, a better understanding 
of both individual- and environmental-level determinants of attendance at public health interventions is required where there is a dearth of current evidence.

Little evidence has been collected on how environmental determinants impact on public health intervention attendance. Tobler's first law of geography proposes that everything is related to everything else, but near things are more related than distant things (29). Accordingly, emerging evidence highlights the importance of proximity for public health interventions, where uptake is generally greater among individuals who live closer to facilities (30-32). For example, in a cross-sectional Swedish study, participants with $\geq 4$ exercise facilities within their neighbourhood spent five more minutes in moderate to vigorous physical activity per day compared to those with no exercise facilities within their neighbourhood (32). While evidence is inconsistent overall (33), some shows that the environment may also impact on intervention outcomes. For instance, within a randomised obesity intervention study, for each mile closer an individual lived to a supermarket, their fruit and vegetable intake increased by 0.29 servings per day and their BMI z-scores reduced by 0.04 units relative to controls (34). Nevertheless, proximity is not immune to health inequalities; with some evidence showing individuals in more affluent areas generally have greater access to public health services and have the social and economic capital to attend such services (35). Such inequalities are highlighted by research which shows how more fastfood outlets in home neighbourhoods are associated with increased consumption of fast-food but more so in those of lower socioeconomic status $(36,37)$. Similarly, while a recent UK based cohort showed that the presence of more physical activity facilities are greenspaces was associated with lower risk of obesity, this association was only seen among those from most affluent segments of society (38). Finally, while recent UK based longitudinal study found inverse associations between park access and fitness facilities and body weight outcomes these were confined to younger adults only (38). Thus, it is plausible that the influence of environmental determinants may be associated with attendance in some age groups more than others perhaps due to differences in mobility patterns (39). However, the interplay between individual- and environmental-level determinants are seldom explored.

This study aims to contribute to the current gap in the literature by examining whether the interplay between individual-level determinants, and environmental-level determinants of proximity and environmental conditions such as weather are likely to be important to inform policy decisions. Specifically, in this study we investigate the influence of a participants (i) proximity to a public health intervention, (ii) the weather and seasonality and (iii) lifestyle practices; on attendance at a city-wide public health intervention for physical activity over one year. We hypothesise that as distance to intervention and weather deteriorates, the likelihood of attendance at the public health intervention decreases. We also examine the hypothesis that there will be differences in associations between environmental determinants and attendance by the sociodemographic characteristics of age, gender, and socioeconomic status. 


\section{Methods}

\subsection{Study Background}

The Leeds Let's Get Active (LLGA) intervention (40) was developed by Leeds City Council as part of Sport England's 'Get Healthy, Get into Sport' funding stream. LLGA is a community-based public health intervention that encourages inactive Leeds residents to "do more activity". Participants engaging in the scheme had free access to 15 Leeds City Council leisure centre swimming pools and gyms on specified days and times. Each week around 150 one-hour long timetabled sessions - predominantly off-peak were available across the participating sites. Recruitment was open to all adults in the local area (Yorkshire, UK). Before engaging in LLGA sessions, participants were given a standard leisure centre induction. Ethical approval was obtained through Leeds Beckett University research ethics committee and all participants provided informed consent (Application Ref: 8364).

\subsection{Study population}

The sample for this study were recruited between April 2015 and March 2016. Anyone who registered or attended LLGA within this time frame was included in the overall sample which contained 25,745 people and included 185,245 visits. Following data cleaning, 6,598 participant's data were excluded on age (i.e. under 16 years old) and five participant's data were removed where distance from a residential postcode to an attended LLGA session exceeded 100 kilometres (62.1 miles). The average distance for these five participants was 109.4 miles. The final number of participants included a sample of 19,142 for analysis, who registered 159,086 visits to the leisure centres between them within the study time frame.

\subsection{Measures and Data Capture}

\subsubsection{Attendance}

Attendance data was captured over the full year from participating leisure centres using a membership number and associated card that was given to all participants at registration or at their first visit. Upon arrival at a LLGA session, participants presented their membership number/card to reception to log their attendance. At this point, data relating to the date of the visit, the venue in which the visit took place and the type of session attended was recorded and stored in an anonymised database. Associated to a participant's membership number/card were data pertaining to their age, gender and residential postcode.

\subsubsection{Demographics and Lifestyle Practices}

Participant data were collected at baseline via an on-line survey incorporated into the LLGA registration process. Demographics were obtained in relation to ethnicity, deprivation, employment, education and 
marital status. Area-level deprivation was defined by LLGA intervention based on the Index of Multiple Deprivation for the lower super output area of residence and how they ranked within Leeds. They were then classified as part of four categories in line with local guidance into: 1) Not a deprived area, 2) Top 3\% Most Deprived Areas in Leeds, 3) 4-10\% Most Deprived Areas in Leeds, 4) 11-20\% Most Deprived Areas in Leeds. For lifestyle practices, participants were asked to self-report the amount of moderate to vigorous intensity physical activity (MVPA) they accumulated over the preceding week $(41,42)$. Based on UK physical activity recommendations (43), participants failing to accumulate the equivalent of $\geq 150$ minutes MVPA were categorised as being insufficiently active, and those achieving $<30$ minutes MVPA as inactive (44). Diet was assessed by summing fruit and vegetable portions ( $\geq 100 \mathrm{gs})$ consumed by participants on a typical day. To follow UK policy guidance, participants were deemed to have an unhealthy diet if they ate less than five portions per day (45). Alcohol consumption was measured using the brief screening tool, AUDIT-C (46). Unhealthy practices in relation to alcohol were recorded for participants scoring four or greater on the test. Participants were also asked about their smoking habits. Current smokers were categorised as presenting this as an unhealthy practice (47). Participant's height and weight were also self-reported to calculate body mass index (BMI). Two subjective wellbeing questions were included within the data collection tool. Participants were asked how satisfied they were with their life and how happy they felt. Both questions were answered on a scale of 0-10 where ' 0 ' was 'not at all' ands ' 10 ' was 'completely'. A score of 0-4 was considered very low, 5-6 was considered low, 7-8 was categorised as medium and 9-10 were high (48). Data on these lifestyle practices were collected for $n=5,280$ participants at baseline. This included only those people who registered from April 2016 and provided the lifestyle data. All other participants were already registered and data were only available for some of their demographics and lifestyle practices.

\subsubsection{Weather Conditions}

Longitudinal weather data were scraped from for each visit and day of the year to account for days of non-attendance from the National Centre for Atmospheric Science, Leeds weather station (Latitude: $53^{\circ}$ 48.36' N, Longitude: $001^{\circ} 33.36^{\prime} \mathrm{W}$, Altitude: 92 metres). The station uses a VantagePro2, controlled by 'weewx', an experimental weather software system written in Python. Weewx was designed to be simple, fast, and easy to understand by leveraging modern software concepts. Data were collected for maximum, minimum and mean daily temperature (Celsius), daily average wind speed (mph) and daily rainfall $(\mathrm{mm})$.

\subsubsection{Proximity}

The data set contained 159,086 records of visit origin and destinations, data were geocoded in ArcGIS Online providing latitude and longitude as well as easting and northing. Ordnance Survey Open Roads was used to model the road network distance from home to leisure centre intervention site. The dataset is an open data source which is good for defining travel by motor vehicle (49). Network distance was calculated using ArcGIS Origin-Destination (OD) Cost Matrix tools using the Network Analysis extension 
with home sector postcode as origin and full postcode of LLGA facility as destination. One of the main advantages of using distance to measure accessibility is that the results, in absolute units, are easily understood by researchers and policy makers (50).

\subsubsection{Study area}

Data from the LLGA study were used to model associations between individual-level and environmental-level determinants and attendance at the LLGA sessions. As shown in Figure 1, Leeds is a large city in West Yorkshire, in the north of England. At the most recent population estimate (2018), the metropolitan district had a total population of 789,194 .

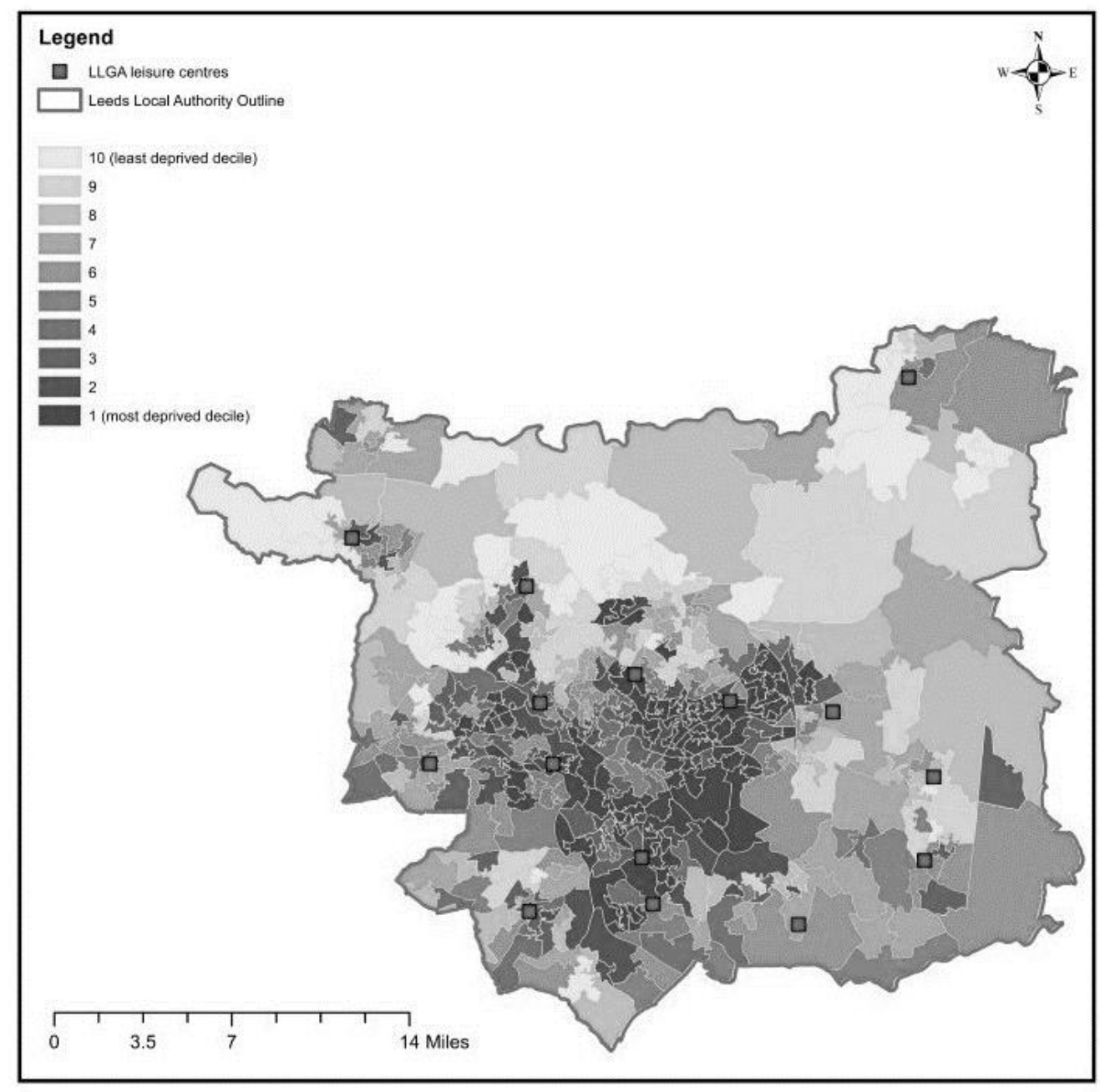

Figure 1. A map showing the location of the study area and the location of LLGA leisure centres with the 2015 Index of Multiple Deprivation. 


\subsection{Statistical Analyses}

Descriptive statistics were used to describe the demographic characteristics of the participants, the incidence of unhealthy practices and health outcomes including BMI among the sample. Independent t-tests and One-Way ANOVAs assessed for differences in proximity and weather conditions for visits by venue, type of session (pool or gym which includes timetabled sessions) undertaken and meteorological season. As data were only available for the date each participant visited from LLGA all other days of the year were extrapolated and categorised as days of non-attendance to provide a binary outcome of attend or not attend on a given day this included the weather for each day. For each participant, the number of days "available" for return visits was defined as the number of days remaining in the study year after the first visit. Once data for weather and environmental variables were extracted for each day of the year this resulted in a dataset of 744,468 days available for return leisure centre visits. Regression models are based on fairly strict parametric assumptions, and research has shown they do not often work well for complex multivariable data sets (51). However, examining such interactions requires powerful data and an ability to model complex interactions between a large number of potential predictor variables or covariates. Regression models are based on fairly strict assumptions with respect to the linearity in parameters and often do not work well for complex multivariable data sets (51). Consequently, we applied a machine learning technique - random forest - to analyse possible effects of weather and demographic models on the leisure centre attendance. The random forest focus on three aspects: the probability that a person will return (i.e., go more than once to a LLGA venue), the number of such return visits, and the probability that a person will go to a leisure centre on a particular day. We focus on the key environmental determinants such as distance to leisure centre, weather and month and then explore any differences by age group and gender in likelihood of attendance. Although flexible, random forest does not produce easily interpretable linear coefficients or p-values. Instead we report the relative importance of the variables, their effect on Mean Squared Error (MSE), and prediction accuracy. To illustrate the effect size, we show what would happen to the sample, if the relevant covariates such as age, gender, ethnicity, employment status, happiness for all the people in the sample were to change to the level of interest (for example, incrementally changing the distance to the nearest facility from $300 \mathrm{~m}$ to $15 \mathrm{~km}$ ) from while keeping the rest as is, other things being equal. In addition to this, we fitted generalised linear models to obtain effect estimates [95\% confidence intervals]. Given the data size, most effects, even when very small in size, would have been expected to be found highly statistically significant. Analyses were carried out in $\mathrm{R}$. 


\section{Results}

\subsection{Descriptive statistics}

The following analyses are based on 19,142 participants attending a LLGA session between $1^{\text {st }}$ April 2015 and $31^{\text {st }}$ March 2016. Table 1 shows that $59.3 \%$ of participants were female and the average age was $39( \pm 15.6)$ years. Of participants providing data, more than three quarters were from a white British ethnic background and $61 \%$ lived in a postcode that was not classified as deprived. Over $60 \%$ were in paid employment, $28.7 \%$ were educated to degree level or higher and $58.2 \%$ were married or cohabiting.

Table 1. Demographic Characteristics of LLGA Participants

\begin{tabular}{|c|c|c|}
\hline DEMOGRAPHICS & PROPORTION & NUMBER \\
\hline \multicolumn{3}{|l|}{ Gender $(n=19,142)$} \\
\hline Female & $59.3 \%$ & 11,352 \\
\hline Male & $40.5 \%$ & 7,749 \\
\hline Prefer not to say & $0.2 \%$ & 41 \\
\hline \multicolumn{3}{|l|}{ Age $(n=19,142)$} \\
\hline $15-24$ & $19.3 \%$ & 3,703 \\
\hline $25-34$ & $26.9 \%$ & 5,142 \\
\hline $35-44$ & $22.6 \%$ & 4,334 \\
\hline $45-54$ & $12.7 \%$ & 2,435 \\
\hline $55-64$ & $10.2 \%$ & 1,948 \\
\hline $65+$ & $8.3 \%$ & 1,580 \\
\hline \multicolumn{3}{|l|}{ Area-level deprivation $(n=5,280)$} \\
\hline Not Deprived Area & $61.0 \%$ & 3,219 \\
\hline Top 3\% Most Deprived Areas in Leeds & $23.5 \%$ & 1,240 \\
\hline 4-10\% Most Deprived Areas in Leeds & $10.0 \%$ & 526 \\
\hline $11-20 \%$ Most Deprived Areas in Leeds & $5.6 \%$ & 295 \\
\hline \multicolumn{3}{|l|}{ Ethnicity $(n=5,280)$} \\
\hline White British & $76.1 \%$ & 4,017 \\
\hline Asian/Asian British & $6.9 \%$ & 363 \\
\hline Black/Black British & $5.1 \%$ & 269 \\
\hline Other & $11.9 \%$ & 631 \\
\hline \multicolumn{3}{|l|}{ Employment Status $(n=5,280)$} \\
\hline Full-Time Paid Employment & $40.0 \%$ & 2,114 \\
\hline Part-Time Paid Employment & $20.2 \%$ & 1,066 \\
\hline Unemployed & $16.7 \%$ & 884 \\
\hline Student & $9.9 \%$ & 524 \\
\hline Retired & $7.9 \%$ & 418 \\
\hline Other & $5.2 \%$ & 274 \\
\hline \multicolumn{3}{|l|}{ Academic $(n=5,280)$} \\
\hline No Qualifications & $16.2 \%$ & 854 \\
\hline GCSE/O Level Grade $A^{*}-C$ & $28.8 \%$ & 1,521 \\
\hline A Levels/Diploma in HE & $26.4 \%$ & 1,392 \\
\hline First Degree (BSc, $B A)$ & $21.5 \%$ & 1,134 \\
\hline Higher Degree (MSc, PhD) & $7.2 \%$ & 379 \\
\hline \multicolumn{3}{|l|}{ Marital Status $(n=5,280)$} \\
\hline Married & $39.7 \%$ & 2,097 \\
\hline Single & $32.5 \%$ & 1,716 \\
\hline Cohabiting & $18.5 \%$ & 977 \\
\hline Divorced/Separated & $4.0 \%$ & 213 \\
\hline Other & $5.3 \%$ & 277 \\
\hline
\end{tabular}




\subsection{Lifestyle practices and environmental data}

At baseline, $86.7 \%$ of participants were not achieving the physical activity guidelines, $81.6 \%$ ate $<5$ portions of fruit and vegetables each day, $16.1 \%$ were current smokers and $45.5 \%$ presented hazardous or harmful alcohol use (Table 2). In addition, $54.5 \%$ of participants reported an unhealthy weight category; the average BMI was 26.4 ( \pm 5.88$)$, and $17.1 \%$ had been clinically diagnosed with a long-term condition. Asthma, depression and diabetes accounted for $68 \%$ of the long-term conditions.

Table 2. Lifestyle practices undertaken by participants

\begin{tabular}{|c|c|c|}
\hline LIFESTYLE PRACTICE & PROPORTION & NUMBER \\
\hline \multicolumn{3}{|l|}{ HEPA Category $(\mathrm{n}=12,541)$} \\
\hline Inactive ( $<30$ mins MVPA/week) & $44.9 \%$ & 5,633 \\
\hline Insufficiently Active (30-149 mins MVPA/week) & $41.3 \%$ & 5,244 \\
\hline Achieve Physical Activity Guidelines & $13.3 \%$ & 1,664 \\
\hline \multicolumn{3}{|l|}{ Daily Fruit \& Vegetable Consumption $(n=5,280)$} \\
\hline None & $7.8 \%$ & 411 \\
\hline 1-4 Portions & $73.8 \%$ & 3,898 \\
\hline 5 or More Portions & $18.4 \%$ & 971 \\
\hline \multicolumn{3}{|l|}{ Current Smoking Status $(n=5,280)$} \\
\hline Never Smoked & $58.4 \%$ & 3,081 \\
\hline Former Smoker & $25.5 \%$ & 1,349 \\
\hline Current Smoker & $16.1 \%$ & 850 \\
\hline \multicolumn{3}{|l|}{ Weekly Alcohol Consumption $(n=5,280)$} \\
\hline Don't Drink Alcohol & $21.4 \%$ & 1,130 \\
\hline Drink Alcohol Responsibly & $33.1 \%$ & 1,746 \\
\hline Excessive Consumption & $45.5 \%$ & 2,404 \\
\hline \multicolumn{3}{|l|}{ Weight Category $(n=3,840)$} \\
\hline Underweight & $2.7 \%$ & 105 \\
\hline Healthy Weight & $45.3 \%$ & 1,741 \\
\hline Overweight & $29.6 \%$ & 1,136 \\
\hline Obese & $22.3 \%$ & 858 \\
\hline \multicolumn{3}{|l|}{ Diagnosed with A Long-Term Condition $(n=5,280)$} \\
\hline No & $82.9 \%$ & 4,379 \\
\hline Yes & $17.1 \%$ & 901 \\
\hline
\end{tabular}

HEPA = Health enhancing physical activity

Table 3 shows the summary data for each visit within the study time frame. It shows the venues attended, the mode of activity undertaken and the meteorological season the visit took place. For each of these, it describes the average distance of each session attended from the participant's residential postcode, and the average temperature, wind speed and rainfall on the day of attendance. The attendance figures for the fifteen different venues varied considerably, with venue one having more than twice as many visits as any other centre. The average distance from residential postcodes also showed sizable variation by centre with figures ranging from around $2.5 \mathrm{~km}$ to around $6 \mathrm{~km}$. The type of session attended by participants at each visit showed swimming to be more popular compared to gym sessions. The average distance from participants residential postcodes was significantly higher for swimming compared to gym sessions $(p<0.001)$. Also, swimming was attended when the daily 
temperature was significantly higher $(p<0.001)$, and wind speed $(p<0.001)$ and rainfall $(p<0.001)$ were significantly lower. In relation to the meteorological season in which attendance took place, the summer months - when the average temperature was highest and average rainfall lowest - generated the most visits. In addition, there was a significant difference in the average distance from participants residential postcode to the venue the visit took place $(p<0.001)$. Post hoc analyses showed that Spring and Summer seasons generated visits with significantly shorter average distances compared to Winter $(p<0.001)$ and Autumn $(p<0.001)$ seasons.

Table 3. Weather and distance from residential postcode by venue, activity mode and season

\begin{tabular}{|c|c|c|c|c|c|}
\hline & $\begin{array}{l}\text { NUMBER OF } \\
\text { VISITS }\end{array}$ & $\begin{array}{l}\text { AVG DIST } \\
\text { (meters) }\end{array}$ & $\begin{array}{l}\text { AVG TEMP } \\
\text { (c) }\end{array}$ & $\begin{array}{c}\text { AVG WIND } \\
(\mathrm{mph})\end{array}$ & $\begin{array}{l}\text { AVG RAIN } \\
(\mathrm{mm})\end{array}$ \\
\hline Total & 159,086 & $3,787.6$ & 10.66 & 4.10 & 0.79 \\
\hline \multicolumn{6}{|l|}{ Venue } \\
\hline Venue 1 & 32,181 & $3,150.9$ & 10.89 & 4.06 & 0.76 \\
\hline Venue 2 & 14,494 & $4,893.9$ & 10.77 & 3.99 & 0.79 \\
\hline Venue 3 & 13,082 & $2,624.0$ & 10.75 & 4.06 & 0.73 \\
\hline Venue 4 & 12,342 & $3,812.5$ & 10.49 & 4.24 & 0.86 \\
\hline Venue 5 & 12,232 & $4,454.2$ & 10.52 & 4.19 & 0.84 \\
\hline Venue 6 & 12,297 & $2,719.4$ & 10.89 & 4.07 & 0.77 \\
\hline Venue 7 & 10,684 & $5,473.0$ & 10.48 & 4.11 & 0.83 \\
\hline Venue 8 & 10,068 & $4,729.8$ & 10.38 & 4.17 & 0.81 \\
\hline Venue 9 & 9,272 & $3,015.8$ & 10.71 & 4.08 & 0.78 \\
\hline Venue 10 & 7,481 & $4,083.6$ & 10.51 & 4.14 & 0.82 \\
\hline Venue 11 & 6,694 & $3,483.5$ & 10.51 & 4.13 & 0.77 \\
\hline Venue 12 & 6,422 & $2,569.3$ & 10.46 & 4.13 & 0.78 \\
\hline Venue 13 & 6,140 & $3,593.6$ & 10.52 & 4.11 & 0.79 \\
\hline Venue 14 & 4,600 & $6,044.6$ & 10.42 & 4.19 & 0.84 \\
\hline Venue 15 & 1,097 & $6,091.1$ & 10.90 & 4.07 & 0.89 \\
\hline \multicolumn{6}{|c|}{ Session Type } \\
\hline Swimming & 84,327 & $3,969.6$ & 10.75 & 4.07 & 0.77 \\
\hline Gym & 73,144 & $3,542.8$ & 10.53 & 4.15 & 0.80 \\
\hline \multicolumn{6}{|l|}{ Season } \\
\hline Spring & 39,039 & $3,685.5$ & 8.82 & 4.13 & 0.73 \\
\hline Summer & 42,170 & $3,738.6$ & 15.63 & 3.54 & 0.65 \\
\hline Autumn & 38,516 & $3,841.3$ & 11.15 & 3.53 & 1.00 \\
\hline Winter & 39,361 & $3,888.9$ & 6.67 & 5.25 & 0.78 \\
\hline
\end{tabular}

3.3 Exploring the relative importance and associations between attendance, sociodemographic, lifestyle practices, and environmental determinants

The full range of sociodemographic and lifestyle practice variables was available for the smaller subset of the dataset $(n=3,621)$. We transformed these data to days visited the leisure centre and no visit of the leisure centre which resulted in a total 744,468 days available for return leisure centre visits. Overall, 15,067 leisure centre visits were made, translating to an average 7.4 visits per year. A total of $37.3 \%$ only went once (the full distribution of the number of visits per person in the sample is shown in supplementary materials Figure S1). This section assesses the probability that a person will return (i.e., go more than once), the number of such return visits and the probability that a person will go to a leisure centre on a particular day. We focus on the key environmental determinants such as distance to leisure 
centre, weather and month and then explore differences by age group and gender in likelihood of attendance.

First, a random forest model was applied to predict the probability of at least one follow-up visit from a range of sociodemographic, lifestyle practices, and environmental variables. It was found that the distance to the leisure centre from home was the single most influential variable (Figure 2; Panel 2A). This means that the distance to the public health intervention, i.e. the leisure centre, had the greatest influence on whether a person who went to the leisure centre once, returned. The changes in expected probability of at least one return visit for the observed sample was conditional on the distance to the leisure centre (Figure 2; Panel 2B). Interestingly, distance to the leisure centre only seems to have an effect after about $5 \mathrm{~km}$ where all or most groups showed a declining trend. When we explored differences by age, gender, and socioeconomic status, distance seemed to have almost no influence on $65+$ year old men. In other analyses which are shown in supplementary materials Figure S2 there was little difference by deprivation and distance to the leisure centre. 


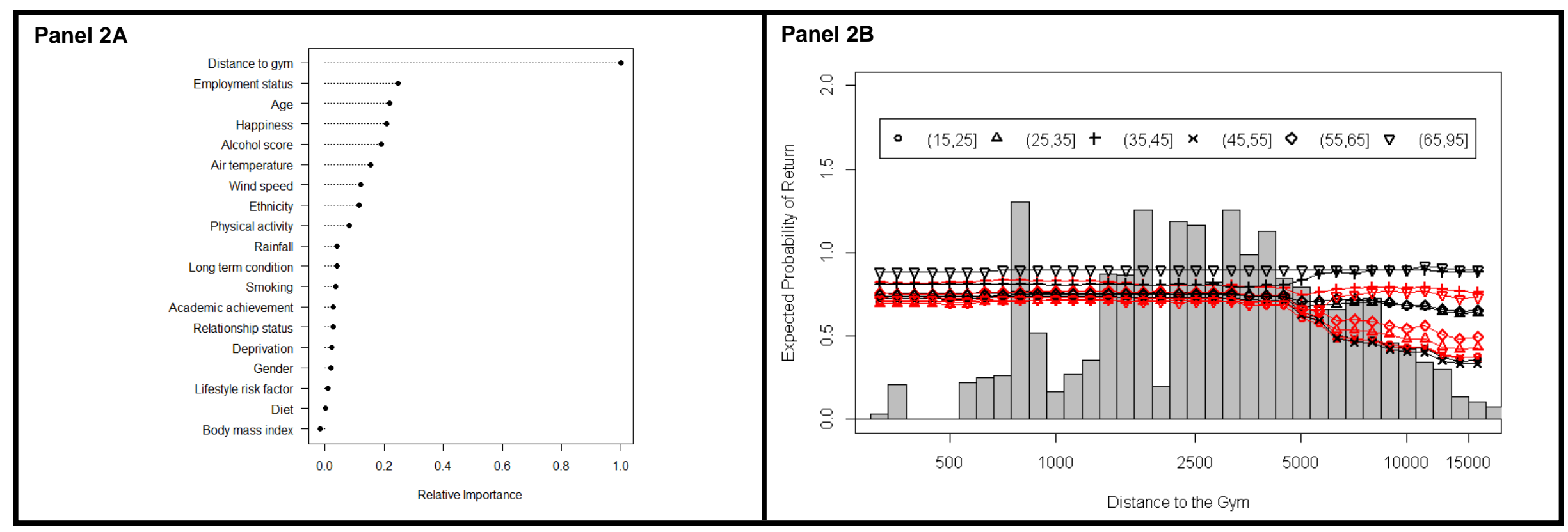

Figure 2. Panel $2 \mathrm{~A}$ shows the relative importance of sociodemographic, lifestyle practices, and environmental variables on the day of the first visit on the probability of return visits. Panel $2 \mathrm{~B}$ shows the expected probability of a return to the leisure centre for the observed sample conditional on the distance to the leisure centre by gender (black = women, red $=$ men) and age (symbol: $\mathbf{O}[15$ to $<25$ years]; $\Delta$ [25 to $<35$ years]; $+[35$ to $<45$ years]; $\mathbf{x}[45$ to $<55$ years]; $\diamond[55$ to $<65$ years]; $\nabla$ [65 years and above]). The histogram in grey shows the current distribution of leisure centre distances for the sample. 
Figure 3 (Panel $3 A$ ) shows the relative significance of variables when predicting the number of return visits. Age group was the single most substantial predictor. In order to assess the size of the effect of distance to the leisure centre on the expected number of visits per year, we have used the random forest model to predict the expected number of visits per year if the entire sample was living within a certain distance from a leisure centre. We varied this distance from $300 \mathrm{~m}$ to $15,000 \mathrm{~m}$ and recorded the minimum and maximum predicted number of visits per year over that range. The results stratified by age and gender are shown in Figure 3 (Panel 3B). For distance to the leisure centre, the difference between the estimates for $300 \mathrm{~m}$ and $15,000 \mathrm{~m}$ was about 7-10 visits per year, this equates to approximately 1 extra visit every 6 weeks. For example, as shown in Figure 3B, for the younger groups, the variations in the distance to leisure centre can increase number of visits from approximately 10 to 15 while for the 45-55 years women it can go from approximately 20-30. Other things being equal, men tended to have more return visits than women, and older people tended to have more return visits than younger people. 


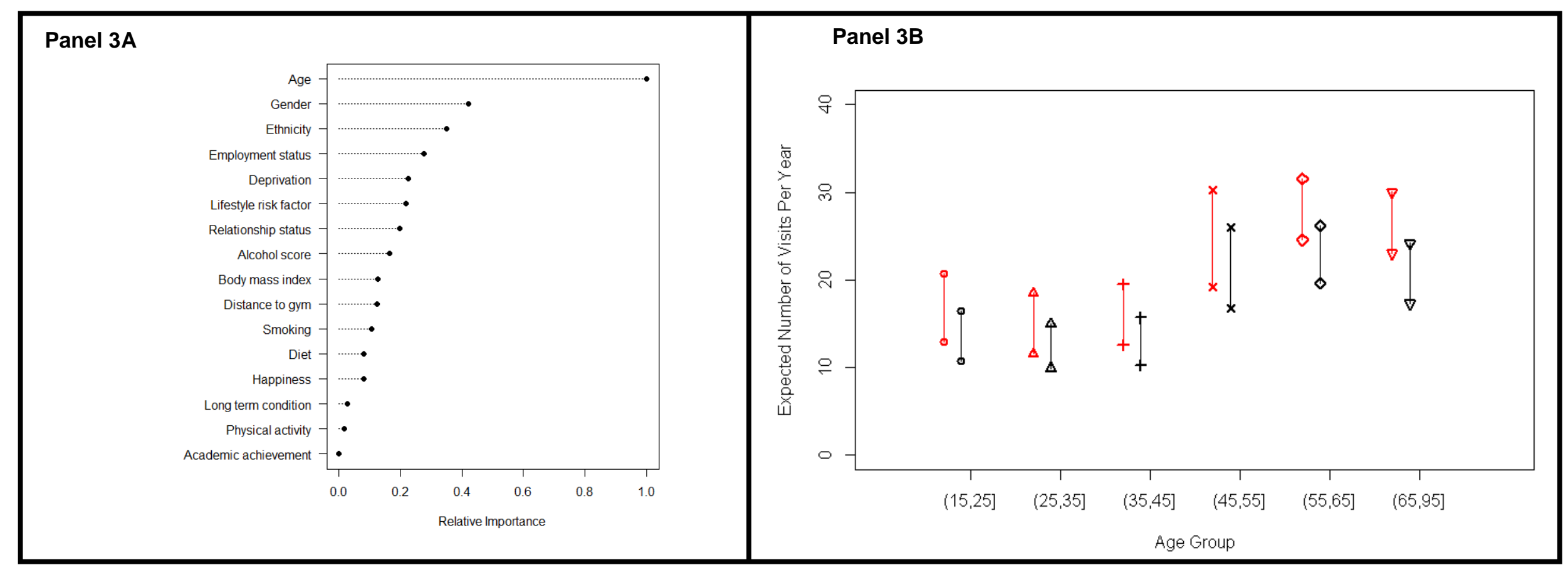

Figure 3. Panel $3 \mathrm{~A}$ shows the relative significance of variables when predicting the number of return visits. Panel $3 B$ highlights the range of expected number of return visits per year for men (red) and women (black) by age group (years) as the distance to the leisure centre varies from $300 \mathrm{~m}$ to $15,000 \mathrm{~m}$. 
We also assessed the effect of environmental conditions such as weather (temperature, rainfall and wind speed), month of the year, and the type of day (weekday/weekend) on whether or not a visit was made on a particular day. The random forest model which did not include weather information had a better model fit than the one with, therefore this is presented. It showed that month was the most significant predictor of attendance (Figure 4; Panel 4A). Specifically, as shown in Figure 4, Panel 4B the summer months were more popular than the winter months. There were again few differences by area-level-deprivation. 


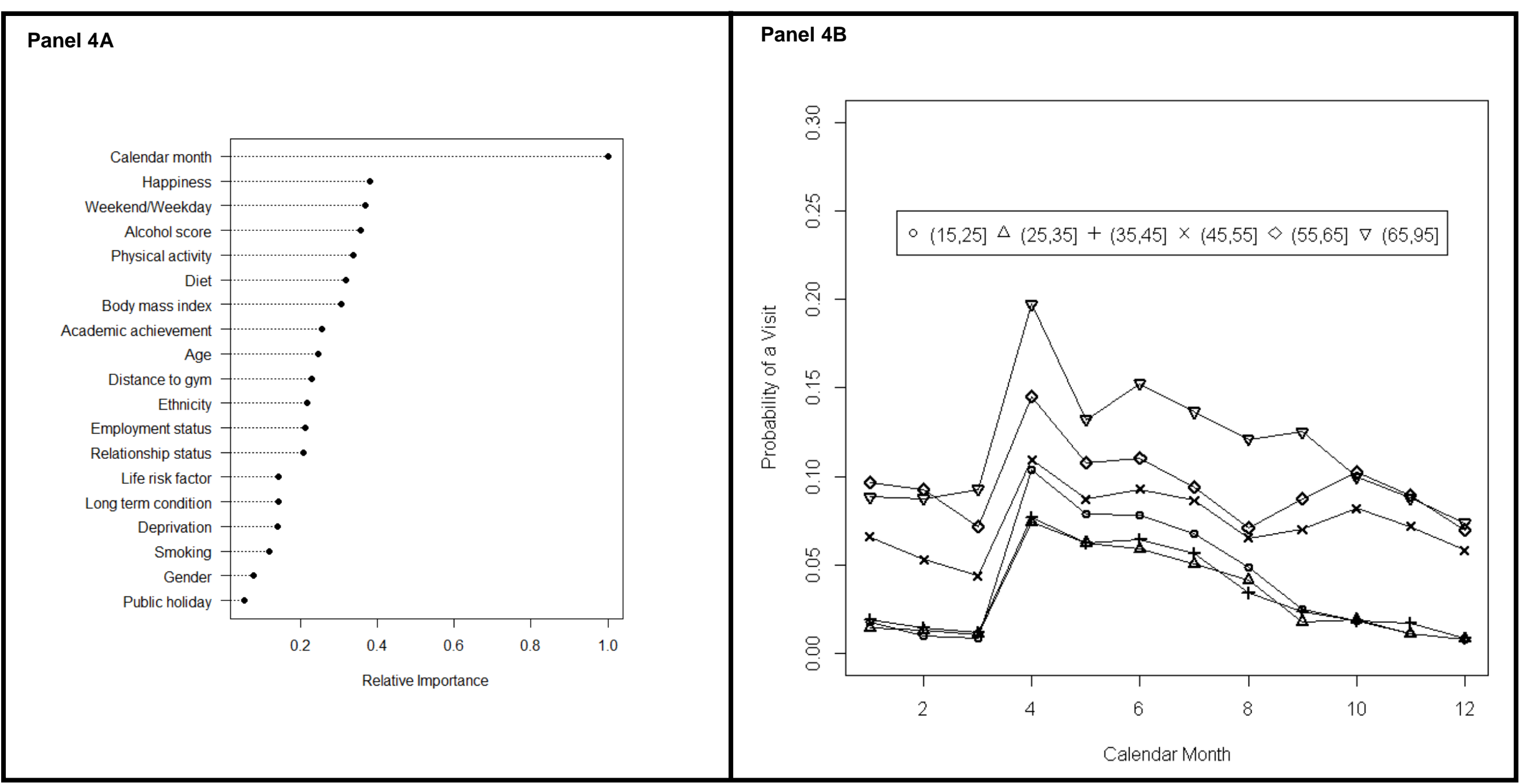

Figure 4. Panel $4 \mathrm{~A}$ shows the relative importance of sociodemographic, lifestyle practices, and environmental variables on whether or not a visit was made on a particular day. Panel 4B highlights the effect of calendar month on the probability of a visit by age group. 


\section{Discussion}

This unique longitudinal study investigated the influence of sociodemographic, lifestyle practices, and environmental variables on attendance at a city-wide physical activity intervention over one year. This is one of the first studies to explore the influence of environmental determinants such as proximity to intervention, weather, and month of year on attendance. We extend evidence by using a large longitudinal sample of participants who registered individual visits to intervention leisure centres over a full year resulting in 744,468 possible days available for return leisure centre visits. Our findings show that wider determinants of attendance such as distance to leisure centre and month of year were important in predicting attendance. We assessed the probability that a person will return (i.e. go more than once), the number of such return visits, and the probability that a person will go to a leisure centre on a particular day. Specifically, we found that the distance to the leisure centre from home was the single most influential determinant in predicting whether a person who went to the leisure centre once, will go back. However, age group was the single most substantial predictor of the number of return visits and other factors such as employment status and level of happiness were also important. While distance to the leisure centre was slightly less important, the difference between the estimates for $300 \mathrm{~m}$ and 15,000m was still about 7-10 visits per year. This equates to approximately 1 extra visit every 6 weeks. Finally, month of the year was the most important determinant on whether or not a visit was made on a particular day accordingly lifestyle practices such as physically activity were also important.

The findings of this longitudinal study which tracked attendance over a year clearly highlight the importance of wider determinants in predicting attendance at a public health intervention for physical activity. Our study adds an important contribution to current evidence which was found little support for the environmental determinants of attendance and physical activity behaviour (28). While previous research often investigates what physical facilities are available within neighbourhoods, they seldom have data on actual use of such facilities (52-54), fewer still have this data available longitudinally. Monitoring attendance over a year, we showed that proximity to leisure centre from home was the most important determinant in determining if a person who went to the leisure centre once, will go back. While most evidence on environmental determinants is inconsistent, our findings support previous evidence which have shown that wider determinants such as weather or proximity to facilities influence attendance at public health interventions (20-22, 28, 30, 32, 55). For example, a recent review showed that the availability of physical activity equipment was convincingly associated with vigorous physical activity and connectivity of trails with active commuting (28) while other evidence from 14 cities in ten countries on five continents has shown that design of urban environments has the potential to contribute substantially to physical activity (30).

Little if any evidence has considered if proximity predicts attendance and how this may vary by demographic variables such as age. Our study shows that proximity (distance via road network) to the 
leisure centre effects whether individuals return, but only from $5 \mathrm{~km}$, and this effect was not evident in older men. For instance, distance to the leisure centre only seemed to have an effect after about $5 \mathrm{~km}$ and had almost no influence on 65+ year old men. While we cannot say specifically, based on previous evidence, we can speculate this could relate to this group's preparedness to navigate distance or could refer to activities they have always done, established patterns of physical activity or a place of social networks (56). Similarly, the summer months were more popular than the winter months. Examining the interaction between individual sociodemographic determinants such as age or socioeconomic status alongside wider determinants such as proximity to leisure centres will be an important direction for future research to enable a better understanding of what environmental determinants are important for specific population groups. For example, previous research has shown that favourable physical activity environments were associated with reduced obesity risk but only among those most affluent populations (57). In contrast, this study showed few differences by socioeconomic status but showed differences in attendance for physical activity by age group. Such variance in findings between studies could be due to a range of factors such as the difference between population groups studied and measures included but serve to highlight the importance of exploring the interaction between individual and environmental determinants of health.

In addition to environmental determinants, other factors including employment status and levels of physical activity at baseline were important in predicting attendance. Social stigma (16), a lack of flexibility in opening hours $(17)$ and irregular working hours $(18,19)$ have previously been highlighted as influencing adherence at public health interventions. Positive relationships between levels of physical activity and happiness have been previously reported in the literature (58-60) however, less literature has examined associations with attendance at a public health intervention. In addition to this, it is important to consider that there are many determinants not captured within this study which may be associated with attendance including aspects like instructor characteristics, social support, self-efficacy and perceived behavioural control (61). While it is not possible to capture every influence on level of attendance this study still makes an important contribution to evidence. This study raises important questions and has implications for both the management of people who don't attend interventions and the effectiveness of existing strategies that aim to increase attendance. Our study details participants engagement patterns within a universal, free-at-the-point-of-access, physical activity intervention. Results are therefore important for both public health and physical activity providers. The findings present evidence that both environmental and socio-demographic factors drive attendance and these factors should be taken into account in the future development of interventions in similar settings.

This study is strengthened by the use of a large sample size at a city-wide intervention which uses complex models to account for the complex nature of the data (51). Second, from a geospatial perspective, the inclusion of data on actual use of facilities and not just assuming that individuals use their nearest leisure centre, is a major strength; in this we add significantly to current evidence in health 
geography (62). Third, we examine attendance across the whole year which means our results are not subject to the effects of seasonality $(15,21)$. This research provides valuable routes to investigate the motives, determinants, and behaviours of attendees with the aspiration of securing detailed insights into the characteristics that support their PA preferences. In doing so, this allows future research to initiate dialogue with such groups to provide detailed insights to shape intervention delivery and design (63). Despite these strengths, this study uses self-reported data for lifestyle practices which is subject to recall bias. In addition, despite being city-wide the results presented here may not be generalisable to other cultures and contexts and should be interpreted with this in mind. While attendance data is longitudinal we only have lifestyle practices at baseline and do not have data relating to a participants work address which could be equally important contributing determinant of attendance. Moreover, this study is limited by a lack of follow up on how people in this dataset changed home residential address during the study period. Our sample was primarily white British and we only have lifestyle practice data on a smaller sample of our larger sample. It is also likely that many of the participants will have undertaken some form of exercise or physical activity outside of the recorded leisure centre visits which may limit the generalisability of the findings. However, the machine learning techniques used, factoring in people's baseline physical activity levels, in some part accounted for some of the variation. In addition, what sessions were available, where, and at what time at this free city wide intervention varied considerably by leisure centre due to opening times and differing policies.

\section{Conclusions}

In summary, we investigated the influence of a participant's proximity to a leisure centres, environmental determinants such as weather, and lifestyle practices on attendance at a city-wide physical activity intervention over one year. This study contributes to the limited research available on associations between environmental influences on public health intervention attendance. It goes beyond much research which rarely has data on actual use of such facilities over time. Triangulation between residential address, data on the geospatial location of facility used over time, and levels of physical activity at baseline make this a unique contribution to evidence. Public health interventions should consider the wider determinants influencing attendance beyond lifestyle and sociodemographic characteristics such a consideration takes on added importance in the emergence of systems-based approaches to physical activity promotion.

\section{Acknowledgements:}

This study was part of the Leeds Let's Get Active study funded by Sport England and Leeds Health and Well-being Board. The authors would like to thank the participants who engaged the study and colleagues from Leeds City Council for their contributions to the research.

\section{Funding:}


This study was part of the Leeds Let's Get Active study funded by Sport England and Leeds Health and Well-being Board. 


\section{References}

1. Berryman JW. Exercise is medicine: a historical perspective. Current sports medicine reports. 2010;9(4):195-201.

2. Lawder R, Harding O, Stockton D, Fischbacher C, Brewster DH, Chalmers J, et al. Is the Scottish population living dangerously? Prevalence of multiple risk factors: the Scottish Health Survey 2003. BMC Public Health. 2010;10:330.

3. Conry MC, Morgan K, Curry P, McGee H, Harrington J, Ward M, et al. The clustering of health behaviours in Ireland and their relationship with mental health, self-rated health and quality of life. BMC Public Health. 2011;11:692.

4. Poortinga W. The prevalence and clustering of four major lifestyle risk factors in an English adult population. Preventive medicine. 2007;44(2):124-8.

5. Khaw K, Wareham N, Bingham S, Welch A, Luben R, Day N. Combined Impact of Health Behaviours and Mortality in Men and Women: The EPIC-Norfolk Prospective Population Study. PLoS medicine. 2008;5:39-47.

6. Hobbs M, Duncan MJ, Collins P, McKenna J, Schoeppe S, Rebar AL, et al. Clusters of health behaviours in Queensland adults are associated with different socio-demographic characteristics. J Public Health (Oxf). 2018.

7. Zwolinsky S, Raine G, Robertson S. Prevalence, Co-Occurrence and Clustering of Lifestyle Risk Factors Among UK Men. Journal of Men's Health. 2016;12(2):15-24.

8. Marmot M. Universal health coverage and social determinants of health. Lancet. 2013;382(9900):1227-8.

9. Petrovic D, de Mestral C, Bochud M, Bartley M, Kivimaki M, Vineis P, et al. The contribution of health behaviors to socioeconomic inequalities in health: A systematic review. Prev Med.

2018;113:15-31.

10. Mozaffarian D, Wilson PW, Kannel WB. Beyond established and novel risk factors: lifestyle risk factors for cardiovascular disease. Circulation. 2008;117(23):3031-8.

11. Newton JN, Briggs AD, Murray CJ, Dicker D, Foreman KJ, Wang H, et al. Changes in health in England, with analysis by English regions and areas of deprivation, 1990-2013: a systematic analysis for the Global Burden of Disease Study 2013. Lancet. 2015;386(10010):2257-74.

12. Fineberg HV. Shattuck Lecture. A successful and sustainable health system--how to get there from here. The New England journal of medicine. 2012;366(11):1020-7.

13. O'Mara-Eves A, Brunton G, Oliver S, Kavanagh J, Jamal F, Thomas J. The effectiveness of community engagement in public health interventions for disadvantaged groups: a meta-analysis. BMC Public Health. 2015;15(1):129.

14. Althoff T, Sosic R, Hicks JL, King AC, Delp SL, Leskovec J. Large-scale physical activity data reveal worldwide activity inequality. Nature. 2017;547(7663):336-9.

15. Aspvik NP, Viken H, Ingebrigtsen JE, Zisko N, Mehus I, Wisloff $U$, et al. Do weather changes influence physical activity level among older adults? - The Generation 100 study. PloS one. 2018;13(7):e0199463.

16. Lyimo RA, Stutterheim SE, Hospers HJ, de Glee T, van der Ven A, de Bruin M. Stigma, disclosure, coping, and medication adherence among people living with HIV/AIDS in Northern Tanzania. AIDS patient care and STDs. 2014;28(2):98-105.

17. Seeley JA, Allison EH. HIV/AIDS in fishing communities: challenges to delivering antiretroviral therapy to vulnerable groups. AIDS care. 2005;17(6):688-97.

18. Mack N, Odhiambo J, Wong CM, Agot K. Barriers and facilitators to pre-exposure prophylaxis (PrEP) eligibility screening and ongoing HIV testing among target populations in Bondo and Rarieda, Kenya: results of a consultation with community stakeholders. BMC health services research.

2014;14:231.

19. Walker L, Ward E, Gambitsis D. Improving New Zealand's childhood immunisation rates: evidence review. Wellington: Allen and Clarke; 2019. 
20. Timmermans EJ, van der Pas S, Dennison EM, Maggi S, Peter R, Castell MV, et al. The Influence of Weather Conditions on Outdoor Physical Activity Among Older People With and Without Osteoarthritis in 6 European Countries. Journal of physical activity \& health.

2016;13(12):1385-95.

21. Harrison F, Goodman A, van Sluijs EMF, Andersen LB, Cardon G, Davey R, et al. Weather and children's physical activity; how and why do relationships vary between countries? Int J Behav Nutr Phys Act. 2017;14(1):74.

22. Tucker $P$, Gilliland J. The effect of season and weather on physical activity: a systematic review. Public Health. 2007;121(12):909-22.

23. Wu YT, Luben R, Wareham N, Griffin S, Jones AP. Weather, day length and physical activity in older adults: Cross-sectional results from the European Prospective Investigation into Cancer and Nutrition (EPIC) Norfolk Cohort. PloS one. 2017;12(5):e0177767.

24. Chan CB, Ryan DA. Assessing the effects of weather conditions on physical activity participation using objective measures. International journal of environmental research and public health. 2009;6(10):2639-54.

25. Feinglass J, Lee J, Semanik P, Song J, Dunlop D, Chang R. The effects of daily weather on accelerometer-measured physical activity. Journal of physical activity \& health. 2011;8(7):934-43.

26. Stensvold D, Bucher Sandbakk S, Viken H, Zisko N, Reitlo LS, Nauman J, et al.

Cardiorespiratory Reference Data in Older Adults: The Generation 100 Study. Med Sci Sports Exerc. 2017;49(11):2206-15.

27. Klenk J, Buchele G, Rapp K, Franke S, Peter R. Walking on sunshine: effect of weather conditions on physical activity in older people. J Epidemiol Community Health. 2012;66(5):474-6.

28. Wendel-Vos W, Droomers M, Kremers S, Brug J, van Lenthe F. Potential environmental determinants of physical activity in adults: a systematic review. Obes Rev. 2007;8.

29. Tobler W. A computer movie simulating urban growth in the Detroit region. Economic Geography. 1970;46:234-40.

30. Sallis JF, Cerin E, Conway TL, Adams MA, Frank LD, Pratt M, et al. Physical activity in relation to urban environments in 14 cities worldwide: a cross-sectional study. Lancet.

2016;387(10034):2207-17.

31. Diez Roux AV, Evenson KR, McGinn AP, Brown DG, Moore L, Brines S, et al. Availability of recreational resources and physical activity in adults. American journal of public health. 2007;97(3):493-9.

32. Eriksson $U$, Arvidsson D, Sundquist K. Availability of exercise facilities and physical activity in 2,037 adults: cross-sectional results from the Swedish neighborhood and physical activity (SNAP) study. BMC Public Health. 2012;12:607.

33. Wilkins E, Radley D, Morris M, Hobbs M, Christensen A, Marwa WL, et al. A systematic review employing the GeoFERN framework to examine methods, reporting quality and associations between the retail food environment and obesity. Health \& place. 2019;57:186-99.

34. Fiechtner L, Kleinman K, Melly SJ, Sharifi M, Marshall R, Block J, et al. Effects of Proximity to Supermarkets on a Randomized Trial Studying Interventions for Obesity. American journal of public health. 2016;106(3):557-62.

35. Chetty R, Stepner M, Abraham S, Lin S, Scuderi B, Turner N, et al. The Association Between Income and Life Expectancy in the United States, 2001-2014. Jama. 2016;315(16):1750-66.

36. Burgoine T, Forouhi NG, Griffin SJ, Brage S, Wareham NJ, Monsivais P. Does neighborhood fast-food outlet exposure amplify inequalities in diet and obesity? A cross-sectional study. The American Journal of Clinical Nutrition. 2016;103(6):1540.

37. Burgoine T, Mackenbach J, Lakerveld J, Forouhi N, Griffin S, Brage S, et al. Interplay of Socioeconomic Status and Supermarket Distance Is Associated with Excess Obesity Risk: A UK CrossSectional Study. International journal of environmental research and public health.

2017;14(11):1290. 
38. Hobbs M, Griffiths C, Green M, Christensen A, McKenna J. Examining longitudinal associations between the recreational physical activity environment, change in body mass index, and obesity by age in 8864 Yorkshire Health Study participants. Social Science and Medicine. 2018.

39. Falkingham J, Sage J, Stone J, Vlachantoni A. Residential mobility across the life course: Continuity and change across three cohorts in Britain. Advances in Life Course Research. 2016;30(Supplement C):111.

40. Zwolinsky S, McKenna J, Pringle A, Widdop P, Griffiths C, Mellis M, et al. Physical Activity and Sedentary Behavior Clustering: Segmentation to Optimize Active Lifestyles. Journal of physical activity \& health. 2016;13(9):921-8.

41. Milton K, Bull FC, Bauman A. Reliability and validity testing of a single-item physical activity measure. Br J Sports Med. 2011;45(3):203-8.

42. Wanner M, Probst-Hensch N, Kriemler S, Meier F, Bauman A, Martin BW. What physical activity surveillance needs: validity of a single-item questionnaire. Br J Sports Med. 2013.

43. Department of Health. Start Active, Stay Active: A report on physical activity for health from the four home countries Chief Medical Officers. London: Department of Health; 2011.

44. Sjostrom M, Oja P, Hagstromer M, Smith B, Bauman A. Health-enhancing physical activity across European Union countries: the Eurobarometer study. Journal of Public Health. 2006;14(5):291-300.

45. National Institute of Health and Clinical Excellence. Guidance on the Prevention, Identification, Assessment and Management of Overweight and Obesity in Adults and Children. London: National Institute of Health and Clinical Excellence.; 2006.

46. Bush K, Kivlahan DR, McDonell MB, Fihn SD, Bradley KA. The AUDIT alcohol consumption questions (AUDIT-C): an effective brief screening test for problem drinking. Ambulatory Care Quality Improvement Project (ACQUIP). Alcohol Use Disorders Identification Test. Archives of internal medicine. 1998;158(16):1789-95.

47. Vartiainen E, Seppala T, Puska P. Validation of self reported smoking by serum cotinine measurement in a community-based study. Journal of Epidemiology and Community Health. 2002;56:167-70.

48. Office for National Statistics (ONS). Personal well-being findings from the Annual Population Survey (APS), with analysis by country, region and individual characteristics) London: ONS; 2016 [Available from:

https://www.ons.gov.uk/peoplepopulationandcommunity/wellbeing/bulletins/measuringnationalw ellbeing/2015to2016.

49. Frew R, Higgs G, Harding J, Langford M. Investigating geospatial data usability from a health geography perspective using sensitivity analysis: The example of potential accessibility to primary healthcare. Journal of Transport \& Health. 2017;6:128-42.

50. Talen E, Anselin L. Assessing spatial equity: an evaluation of measures of accessibility to public playgrounds Environment and Planning. 1998;30:595-613.

51. Miguel-Hurtado O, Guest R, Stevenage SV, Neil GJ, Black S. Comparing Machine Learning Classifiers and Linear/Logistic Regression to Explore the Relationship between Hand Dimensions and Demographic Characteristics. PloS one. 2016;11(11):e0165521.

52. Panter J, Guell C, Prins R, Ogilvie D. Physical activity and the environment: conceptual review and framework for intervention research. The international journal of behavioral nutrition and physical activity. 2017;14:156.

53. Den Braver NR, Lakerveld J, Rutters F, Schoonmade L, Brug J, Beulens JWJ. Built environmental characteristics and diabetes: a systematic review and meta-analysis. BMC Med. 2018;16(1):12.

54. Smith L, Foley L, Panter J. Activity spaces in studies of the environment and physical activity: A review and synthesis of implications for causality. Health \& place. 2019;58:102113. 
55. Aspvik NP, Viken H, Ingebrigtsen JE, Zisko N, Mehus I, Wisløff U, et al. Do weather changes influence physical activity level among older adults? - The Generation 100 study. PloS one.

2018;13(7):e0199463-e.

56. Thandi MKG, Phinney A, Oliffe JL, Wong S, McKay H, Sims-Gould J, et al. Engaging Older Men in Physical Activity: Implications for Health Promotion Practice. American journal of men's health. 2018;12(6):2064-75.

57. Hobbs M, Griffiths C, Green M, Jordan H, Saunders J, McKenna J. Associations between the combined physical activity environment, socioeconomic status, and obesity: a cross-sectional study. Perspect Public Health. 2017:1757913917748353.

58. Fisher JJ, Kaitelidou D, Samoutis G. Happiness and physical activity levels of first year medical students studying in Cyprus: a cross-sectional survey. BMC Medical Education. 2019;19(1):475.

59. Galper D, Trivedi M, Barlow C, Dunn A, Kampert J. Inverse Association between Physical Inactivity and Mental Health in Men and Women. Medicine \& Science in Sports \& Exercise. 2006;38(1):173-8.

60. Richards J, Jiang X, Kelly P, Chau J, Bauman A, Ding D. Don't worry, be happy: cross-sectional associations between physical activity and happiness in 15 European countries. BMC Public Health. 2015;15(1):53.

61. Bauman AE, Reis RS, Sallis JF, Wells JC, Loos RJF, Martin BW. Correlates of physical activity: why are some people physically active and others not? The Lancet. 2012;380(9838):258.

62. Hobbs $M$, Atlas J. Environmental influences on behaviour and health: a call for creativity and radical shifts in thinking within contemporary research. N Z Med J. 2019;132(1505):97-9.

63. Eldredge L, Markham C, Ruiter R, Fernández M, Kok G, Parcel G. Planning health promotion programs: an intervention mapping approach. London: John Wiley \& Sons; 2016. 


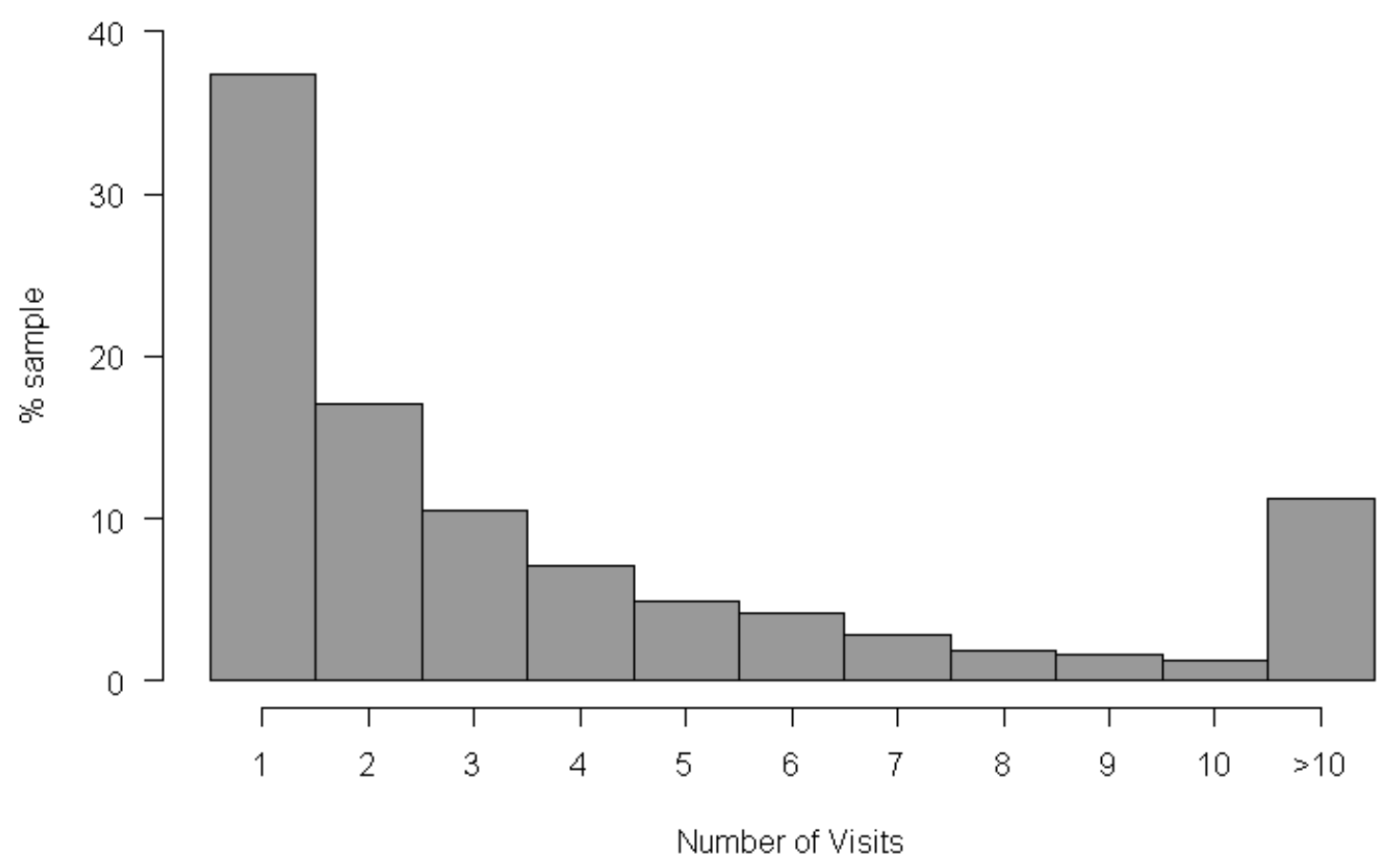

Figure S1. Distribution of the number of visits per person in the sample. 


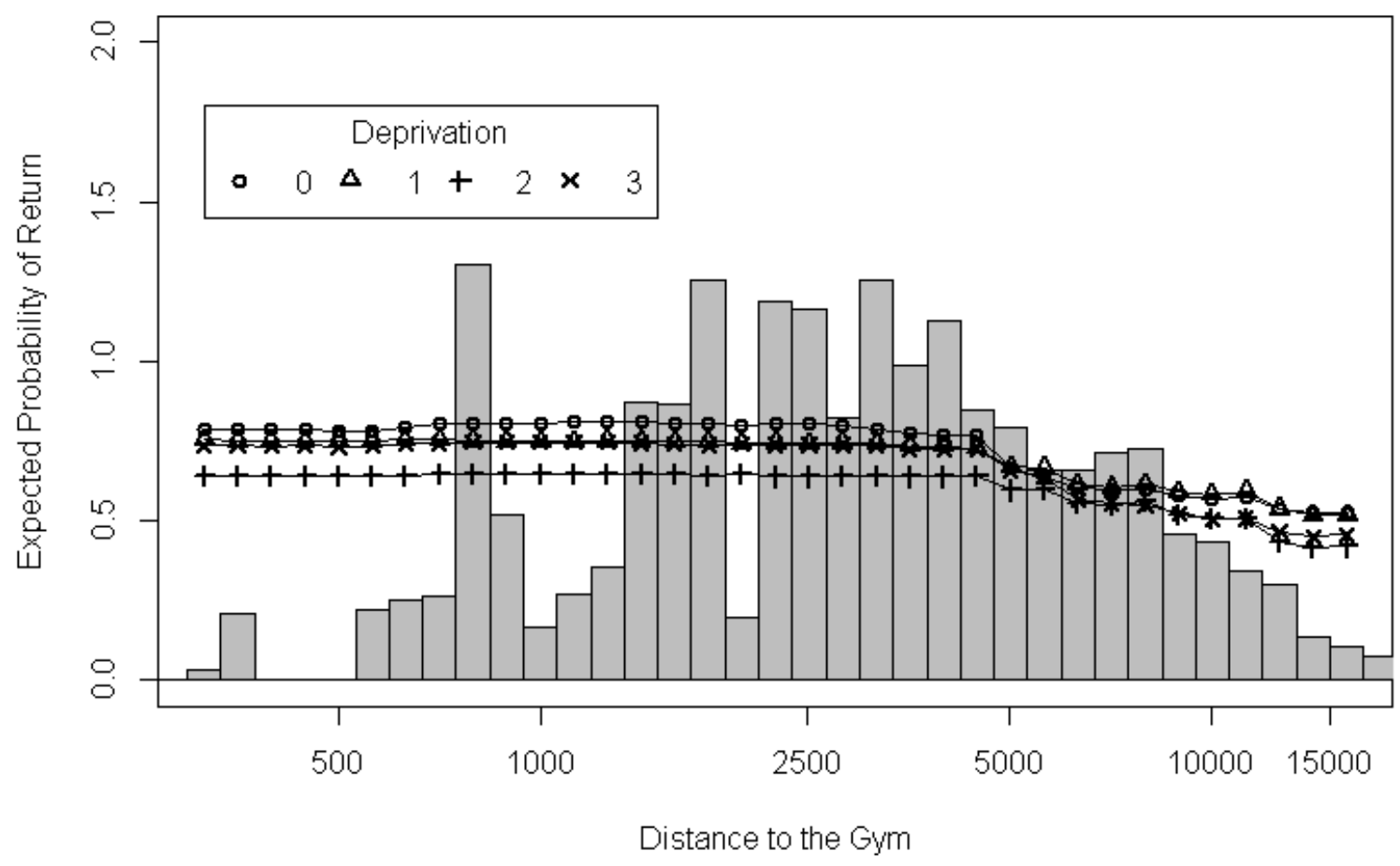

Figure S2. The expected probability of a return to the leisure centre for the observed sample conditional on the distance to the leisure centre by deprivation level $(0=3 \%$ most deprived; $1=10 \%$ most deprived; $2=20 \%$ most deprived; and $3=$ not deprived). The histogram in grey shows the current distribution of leisure centre distances for the sample. 

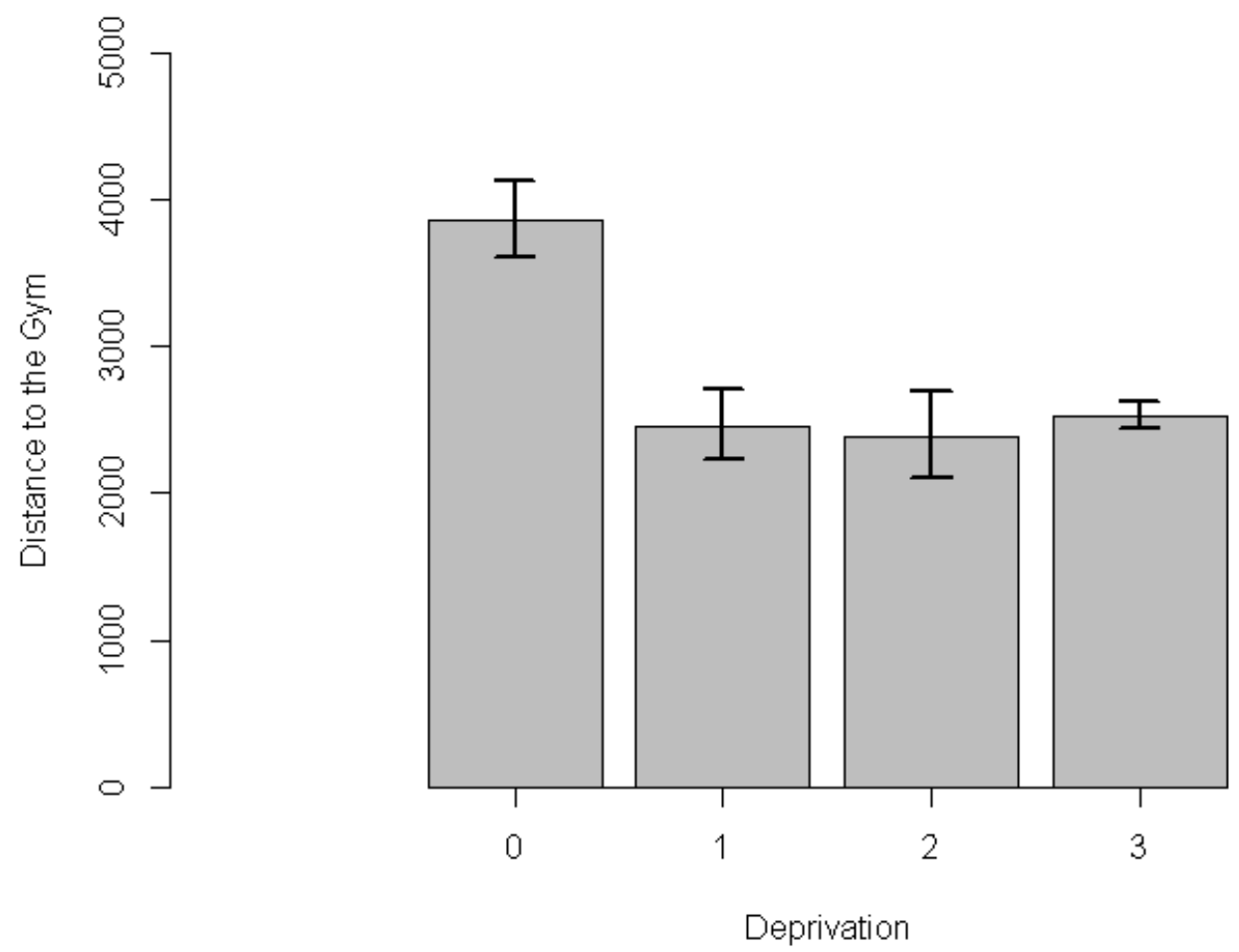

Figure S3. Distance to the leisure centre $(\mathrm{m})$ by deprivation class $(0=3 \%$ most deprived; $1=10 \%$ most deprived; $2=20 \%$ most deprived; and $3=$ not deprived). 